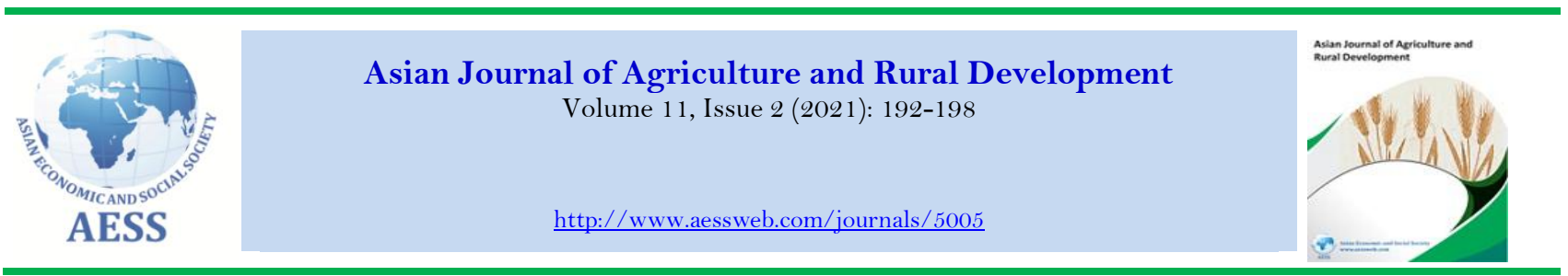

\title{
EFFECT OF PLANTING TIME ON GROWTH AND CORM YIELD OF CHINESE WATER CHESTNUT (Eleocharis dulcis) IN THE MEKONG DELTA, VIETNAM
}

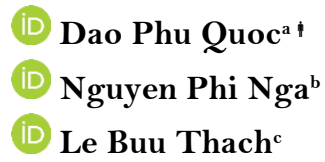

Article History

Received: 5 April 2021

Revised: 10 May 2021

Accepted: 8 June 2021

Published: 1 July 2021

\section{Keywords}

Mekong Delta

Eleocharis dulcis

Chinese water chestnut

Cultivated

Crop

Yield.

\begin{abstract}
aniversity of Sciences, Ho Chi Minh City, Vietnam; Viet Nam National University, Ho Chi Minh City, Vietnam; Institute of Environment and Resources, Ho Chi Minh City, Vietnam.

${ }^{b}$ University of Sciences, Ho Chi Minh City, Vietnam; Viet Nam National University, Ho Chi Minh City, Vietnam.

'Southern Institute of Ecology, Vietnam Academy of Science and Technology, Ho Chi Minh City, Vietnam.
\end{abstract}

\section{$\triangle$ quoccmina@gmail.com (Corresponding author)}

Contribution/Originality: This study is one of very few studies to have investigated the effects of planting seasons on growth and corm yield of Chinese water chestnut (Eleocharis dulcis) in the Mekong Delta, Vietnam; This study provides information about the most suitable times of the year for culture.

DOI: $10.18488 /$ journal.ajard.2021.112.192.198

$\operatorname{ISSN}(\mathrm{P}):$ 2304-1455/ ISSN(E): 2224-4433

How to cite: Dao Phu Quoc --- Nguyen Phi Nga --- Le Buu Thach (2021). Effect of Planting Time on Growth and Corm Yield of Chinese Water Chestnut (Eleocharis dulcis) in the Mekong Delta, Vietnam. Asian Journal of Agriculture and Rural Development, 11(2), 192-198. 10.18488/journal.ajard.2021.112.192.198 (C) 2021 Asian Economic and Social Society. All rights reserved.

\section{INTRODUCTION}

Chinese water chestnut (Eleocharis dulcis (Burm.f.) Trin. ex Hensch.) is cultivated in many parts of the world. It was introduced to the USA (Orlando, FL) in 1930, where its yield was 92 tons/ha (Morton, Sanchez, \& Snyder, 1988). This species is also cultivated in Australia, with an average yield of 20 tons/ha (Kleinhenz, Midmore, \& Geoff, 2001). According to Mei, Kleinhenz, Lyall, and Midmore (2000), photoperiod and temperature both affect the growth 
and development of water chestnut. These factors also affect yield and the ratio of tuber biomass to total fresh biomass (Mei et al., 2000). According to Meili and Kleinhenz, the critical photoperiod is 12.0-12.5 h (Kleinhenz et al., 2001; Mei et al., 2000) and seed corms are best planted when the minimum soil temperature is above $13^{\circ} \mathrm{C}$. Corm formation was retarded by long days and promoted by photoperiods below a critical maximum (Mei et al., 2000). In the Mekong Delta in Vietnam, the photoperiod rises from 11.2 hours in January to 12.6 hours in July. The lowest average monthly temperature is in January $\left(24 \pm 1^{\circ} \mathrm{C}\right)$, and the highest average monthly temperature is in May $(28 \pm$ $\left.1^{\circ} \mathrm{C}\right)$. We propose that water chestnut can be cultivated according to the information recommended by the abovementioned studies. This study examined the cultivation of water chestnut in the Mekong Delta; specifically, we examined the affect of different times of planting on plant performance.

\section{MATERIALS AND METHODS}

Experiments were conducted at Can Tho City in the Mekong Delta ( $\left.9^{\circ} 57^{\prime} 40.51^{\prime \prime} \mathrm{N}, 105^{\circ} 46^{\prime} 36.70^{\prime \prime} \mathrm{E}\right)$ in 2018 and 2019. The plants were planted at six different times and harvested after four months, as shown in Table 1.

Table-1. Summary of planting and harvesting dates, range of photoperiod and mean temperature from six experiments.

\begin{tabular}{c|c|c|c|c}
\hline Experiment & Planting date & $\begin{array}{c}\text { Harvesting } \\
\text { date }\end{array}$ & Photoperiod & Mean temperature $\left({ }^{\circ} \mathrm{C}\right)$ \\
\hline 1 & 01 Jan & 30 April & $11: 33-12: 28$ & 28.3 \\
\hline 2 & O1 Mar & 30 June & $11: 55-12: 25$ & 29.1 \\
\hline 3 & O1 May & 30 Aug & $12: 28-12.42$ & 28.6 \\
\hline 4 & 01 July & 30 Oct & $11: 48-12.42$ & 28.2 \\
\hline 6 & O1 Sep & 30 Dec & $11: 32-12: 18$ & 28.4 \\
\hline
\end{tabular}

Monthly maximum, minimum, and mean temperatures are presented in Table 2.

Table-2. Monthly max and min temperatures $\left({ }^{\circ} \mathrm{C}\right)$ in Can Tho from January 2018 to February 2019.

\begin{tabular}{|c|c|c|c|c|c|c|c|c|c|c|c|c|c|c|}
\hline \multicolumn{15}{|c|}{ Day/month } \\
\hline $\begin{array}{c}\text { Temperature } \\
\left({ }^{\circ} \mathrm{C}\right)\end{array}$ & Jan. & Feb. & Mar. & Apr. & May. & Jun & Jul. & Aug. & Sep. & Oct. & Nov. & Dec. & Jan. & Feb \\
\hline Max & 32.5 & 33.6 & 34.9 & 35.7 & 35.4 & 33.8 & 33.6 & 33.7 & 33.7 & 33.7 & 33.7 & 34.9 & 32.5 & 33.5 \\
\hline Min & 20.6 & 21 & 24 & 24 & 24 & 23.2 & 22.7 & 22.3 & 22.5 & 23.5 & 22.3 & 23.1 & 20.6 & 21.1 \\
\hline Average & 26.5 & 27.3 & 29.4 & 29.8 & 29.7 & 28.5 & 28.2 & 28.0 & 28.1 & 28.6 & 28 & 29 & 26.5 & 27.3 \\
\hline
\end{tabular}

Chinese water chestnut corms were selected with weight ranging from 20 to $25 \mathrm{~g} / \mathrm{corm}$. They were placed in six foam boxes filled with moist clay soil and kept in a cooler at $5^{\circ} \mathrm{C}$. For each experiment, we took one foam box with corms and covered them with moist soil in polyethylene terephthalate glasses $(5 \mathrm{~cm}$ diameter, $10 \mathrm{~cm} \mathrm{depth).} \mathrm{After} 15$ days, when the seedlings had an average of 12 stalks and an average height of $30-40 \mathrm{~cm}$, we moved the plants to a polystyrene box $(25 \times 25 \mathrm{~cm}$ and $28 \mathrm{~cm}$ deep), in which the depth of the soil layer was $23 \mathrm{~cm}$. Each experiment included 30 plants.

The potted plants were grown under natural light and watered twice a day to ensure that there was always a thin layer of water $(1-3 \mathrm{~cm})$ on the soil. Each pot was fertilized with $10 \mathrm{~g}$ of $\mathrm{NPK}\left(\mathrm{N} 20 \%, \mathrm{P}_{2} \mathrm{O}_{5} 20 \%, \mathrm{~K}_{2} \mathrm{O} 15 \%\right)$ every 30 days.

Every month we measured chlorophyll fluorescence, the number of stems, and number of blooming stems per plant, selecting mature stems in each bush and randomly measuring 30 mature stems in one box. We measured stem length and diameter and tracked corm formation. The plants were harvested 120 days after planting, and the total number of stems counted and their diameter and length were recorded. We also weighted the total mass of the stems/box. Plant parts were dried in an oven for $72 \mathrm{~h}$ at $70^{\circ} \mathrm{C}$. Total soluble solids $\left(\right.$ Brix $\left.{ }^{\circ}\right)$ was determined as tree brown corm per box. The corms were peeled and ground, and juice extracted using a blender. We filtered the juice through Whatman filter paper, centrifuged it at 10,000 rpm for $10 \mathrm{~min}$, collected the extract, and measured the Brix value with a refractometer. Chlorophyll fluorescence was measured using the Handy PEA (Hansatech, Kings Lynn, UK) with mature leaves from three plants in each sample. To evaluate the correlation of active variables (photoperiod, temperature $\left({ }^{\circ} \mathrm{C}\right)$, stem number, stem height $(\mathrm{cm})$, stem diameter $(\mathrm{cm})$, flower, stem weight $(\mathrm{g})$, root weight $(\mathrm{g})$, corm weight $(\mathrm{g})$, corm number, total weight $(\mathrm{g})$, \% bearing flowers, corm size $(\mathrm{g}))$ and between observed variables (planting times: Jan, March, May, July, Sep (E1, E2, E3, E4, E5, and E6, respectively)), the data were analyzed using ANOVA at the $95 \%$ confidence level $(P=0.05)$. In order to determine differences in parameters, rate relationship prices were equal to leaner regression. In addition, comparisons between experiments were done by factor analysis using the software XLSTTAT 2020 by applying principle component analysis (PCA). In this study, PCA is based on a correlation matrix and is forced to select two principal components, which together account for more than $75 \%$ of variation in the data. 


\section{RESULTS}

\subsection{Chlorophyll Fluorescence}

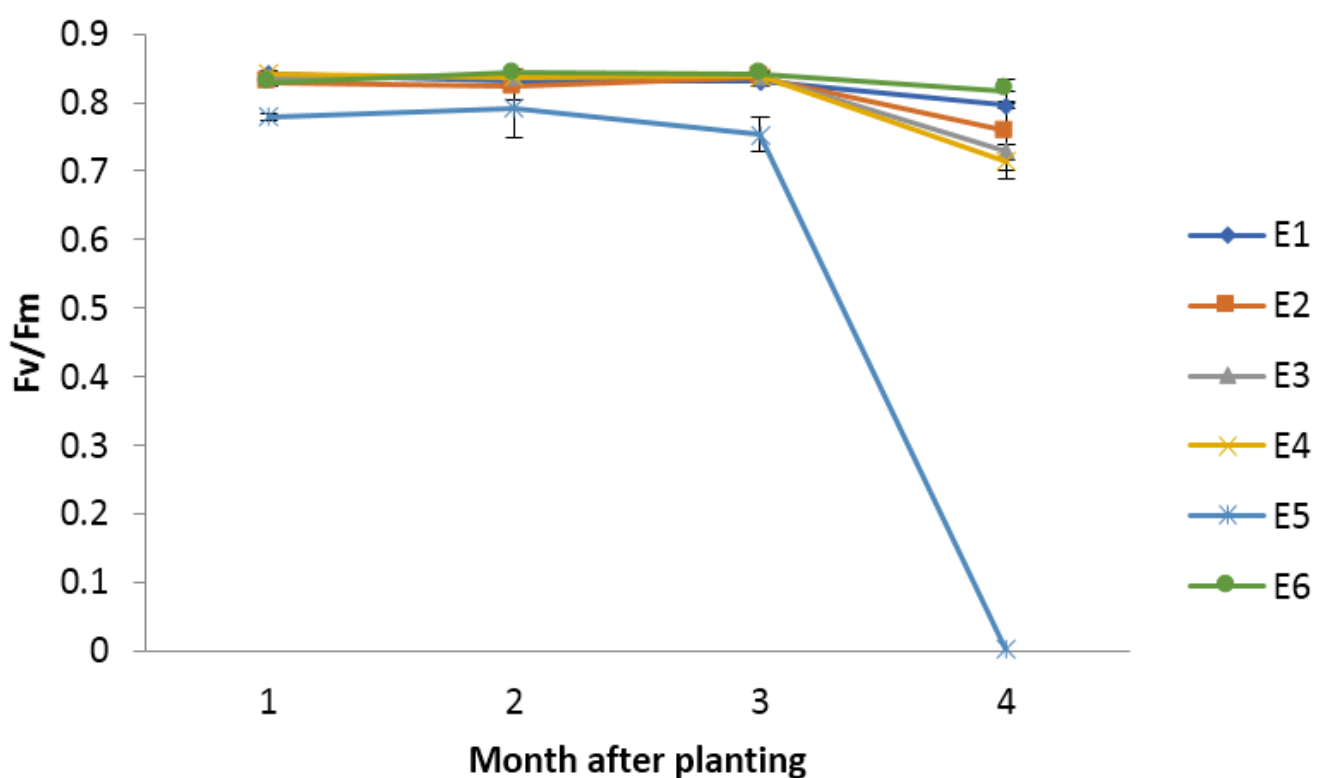

Figure-1. Effected of time of planting on chlorophyll fluorescence in Chinese water chestnut in Vietnam. The plants were planted in Jan. (E1), March (2), May (E3), July (E4), Sept. (E5), and Nov. (E6) and harvested after four months. Data are the means of plant treatment (statistical analysis of each pair showed no difference between $\mathrm{E} 1, \mathrm{E} 2, \mathrm{E} 3, \mathrm{E} 4$, and E6 - only E5 was statistically significant different $(\alpha=0.05, P<0.01)$.

According to previous studies and values, FV/Fm of $0.75-0.86$ is an indicator of healthy plants while $0.60-0.75$ indicates stressed plants (Critchley, 1998). All plants had acceptable values of $\mathrm{Fv} / \mathrm{Fm}$ except for the first time of planting at crop harvest (Figure 1).

\subsection{Growth and Development}

\subsubsection{Number of Stems}

The number of stems doubled in the first two months of plant growth, and the main bush of each plant produced 2-3 additional bushes by means of rhizome division (Figure 2). Each adult bush maintained an average of 14-18 stems (up to 24 stems/bush) and, on average, stem growth rate tripled after two months.

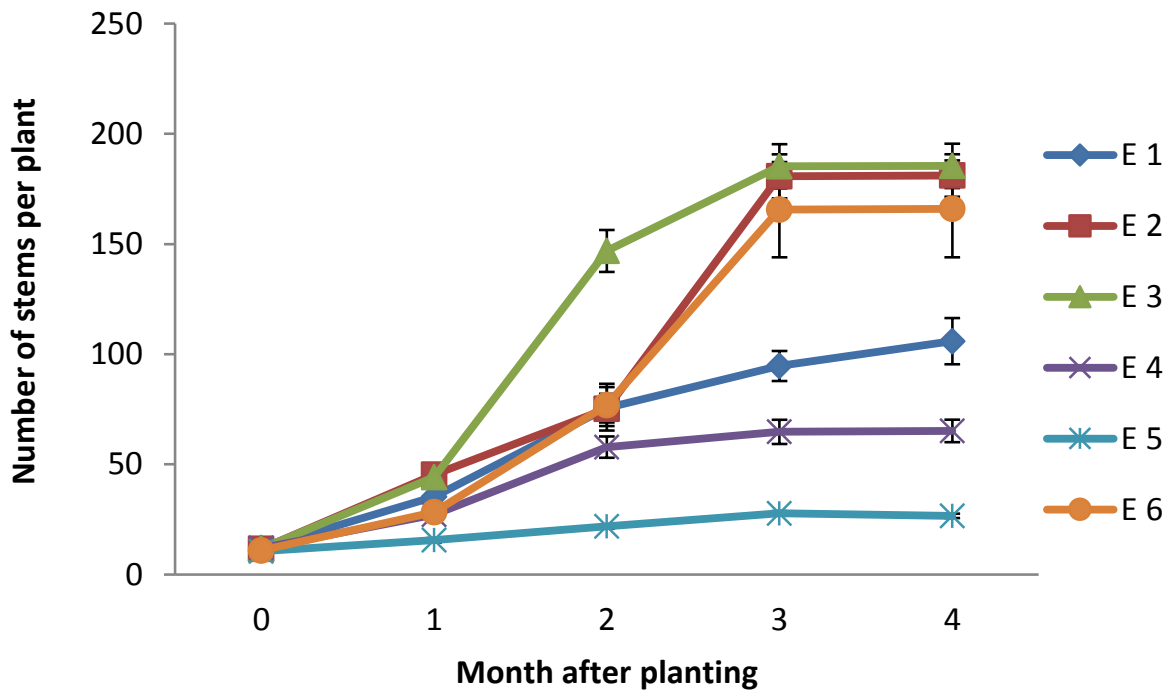

Figure-2. Stem number increase by month. The plants were planted in Jan (E1), March (E2), May (E3), July (E4), Sept (E5), and Nov (E6) and harvested after four months. Data are the means of plant treatment. The number of stems was different among the experiments and was statistically significant $(\alpha=0.05, P$ $<0.01)$.

The number of stems was lower in E4 and E5 than in E1, E2, E3 and E6. These results suggest that early or late plantings are best commerce production in this area. 


\subsubsection{Stem Height}

Stem height increased rapidly in the first two months of growth, except for E1 and E6 where it was slower (Figure 3). Stem height was lower in E.6 than in the other treatments.

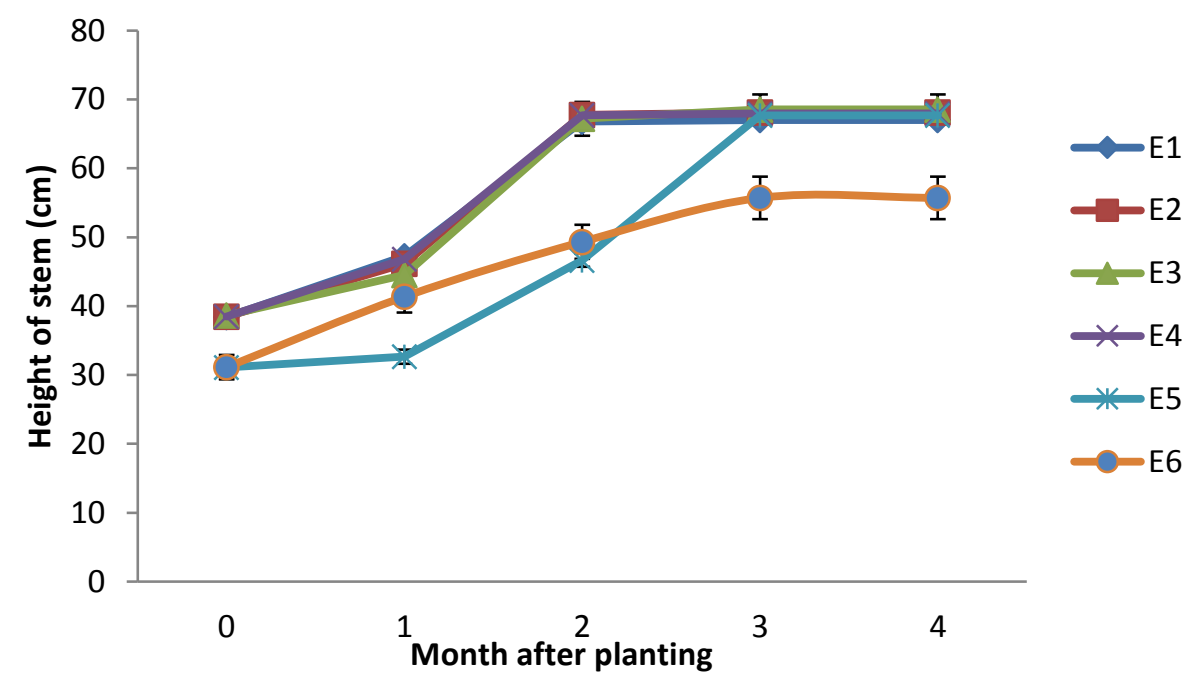

Figure-3. Stem height increase by month. The plants were planted in Jan (E1), March (E2), May (E3), July (E4), Sept (E5), and Nov (E6) and harvested after four months. Data are the means of plant treatment.

\subsubsection{Stem Diameter}

Increases in stem diameter were greatest in the first two months after plating (Figure 4). Final stem diameter was highest in E3, intermediate in E1, E2, E4, and E6, and lowest in E5.

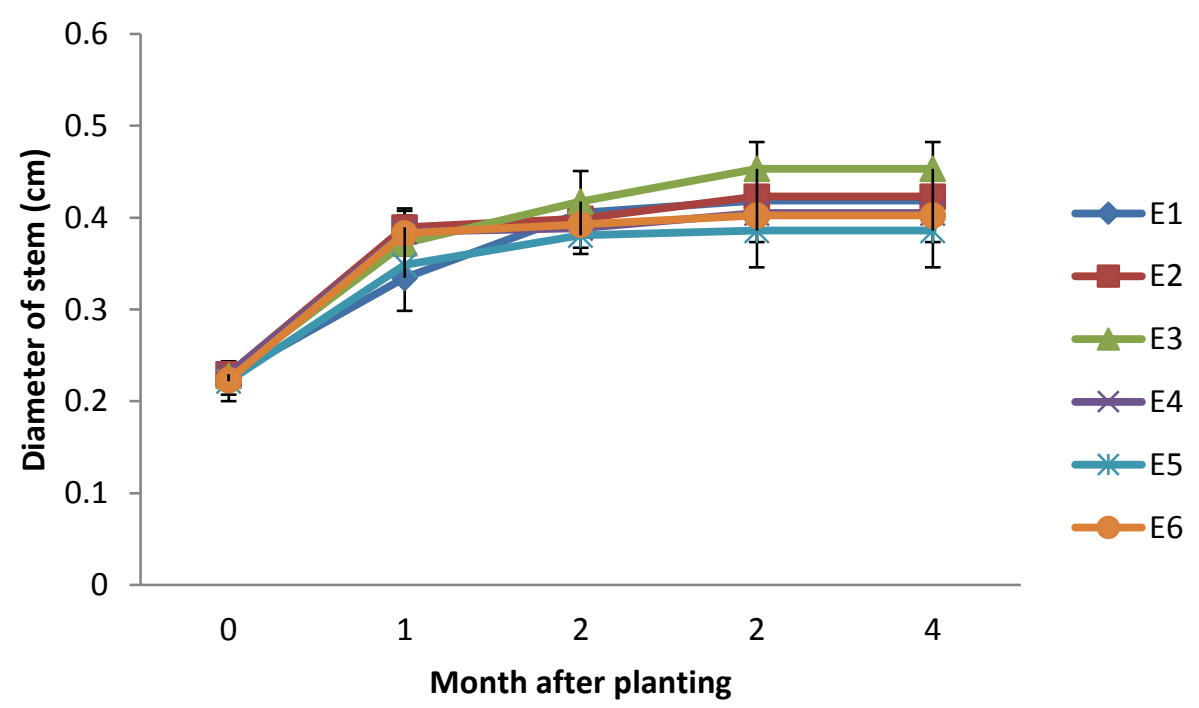

Figure-4. Stem diameter increase by month. The plants were planted in Jan (E1), March (E2), May (E3), July (E4), Sept (E5), and Nov (E6) and harvested after four months. Data are the means of plant treatment. Average stem diameter among experiments with the same date was significantly different $(\alpha=$ $0.05, P<0.01)$.

\subsection{Harvesting Biomass}

Biomass of aboveground plant parts (stems) accounted for $42 \%$, and biomass of belowground parts (roots/rhizomes and corms) accounted for 58\% (Figure 5). This showed that the plants tended to accumulate belowground biomass more than the aboveground biomass. The total fresh biomass of experiment E3 was the highest ( $1337 \mathrm{~g} /$ box $)$, followed by E2 and E6. The ratio of stem biomass/total biomass in E1 was the highest with up to 50\% of the total biomass, leading to lower corm biomass, compared to E3 and E6. The lowest stem biomass/total biomass $(34 \%)$ was recorded for E1. The fresh weight of stems in E6 and E1 was lower than that of corms, indicating a tendency of biomass accumulation in corms at this period of growth. 


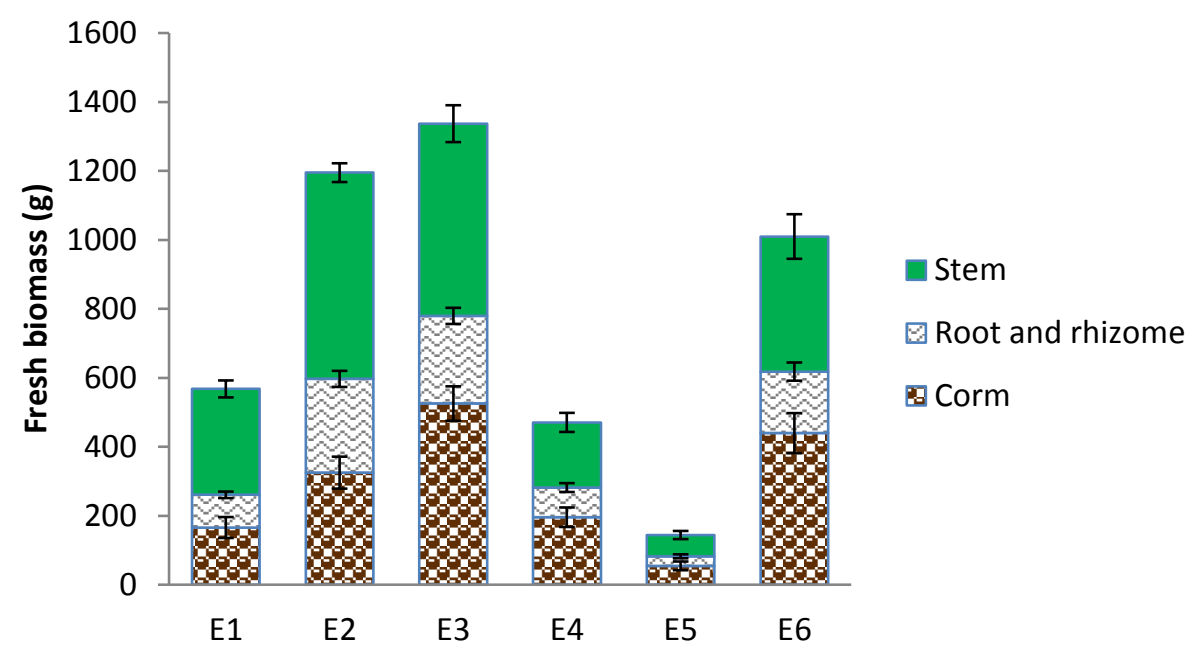

Figure-5. Fresh biomass of stems, roots and rhizomes, and corms. The plants were planted in Jan (E1), March (E2), May (E3), July (E4), Sept (E5), and Nov (E6) and harvested after four months. There were significant difference between the six treatments $(\alpha=0.05, P<0.01)$.

\subsection{Size and Number of Corms}

The size and number of corms in all experiments were different $(P<0.01)$, but there were similarities between $\mathrm{E} 1$ and E3. The size of corms harvested from the six experiments was lower than for the parent corm (25 g/corm), and thus the environmental conditions in Can Tho may have had a negative impact on corm size.

Table-3. Corm numbers and average corm size in experiments.

\begin{tabular}{l|c|c|c|c|c|c}
\hline Parameter & E1 & E2 & E3 & E4 & E5 & E6 \\
\hline Bloom stems (\%) & 5.0 & 6.0 & 21.0 & 48.0 & 2.0 & 1.0 \\
\hline Number of corms & 11.6 & 23.6 & 37.4 & 20.4 & 5.9 & 73.9 \\
\hline Largest corm (g) & 18 & 17 & 18 & 14 & 13 & 12 \\
\hline Smallest corm (g) & 5 & 7 & 6 & 5 & 3 & 1 \\
\hline Average corm weight & $14.3^{\mathrm{a}}$ & 13.8 & $14.1^{\mathrm{a}}$ & 9.8 & 9.3 & 6.0 \\
\hline Total fresh biomass of corm (g/plant) & 116 & 325 & 525 & 196 & 55 & 440 \\
\hline Total fresh biomass of stem & 112 & 598 & 557 & 189 & 62 & 830 \\
\hline Total fresh biomass of root and rhizome & 51 & 272 & 254 & 86 & 28 & 178 \\
\hline
\end{tabular}

Note: There is a statistically significant difference between cells on the same row $(\alpha=0.05, \mathrm{P}<0.01)$, except between two cells with the same symbol (a).

The average size of corms harvested in experiment E1 was highest and that of E6 is the lowest, while the total corm biomass of E3 was the highest (Table 3). All corms harvested from six experiments were less than $19 \mathrm{~g} / \mathrm{corm}$. Perhaps the environmental conditions of the growing region had an influence on corm size. The size of corms was dissimilar among the six treatments, being statistically significant $(\alpha=0.05, \mathrm{P}<0.01)$, except in the case of mediumsized corms for E1 and E3, which were similar.

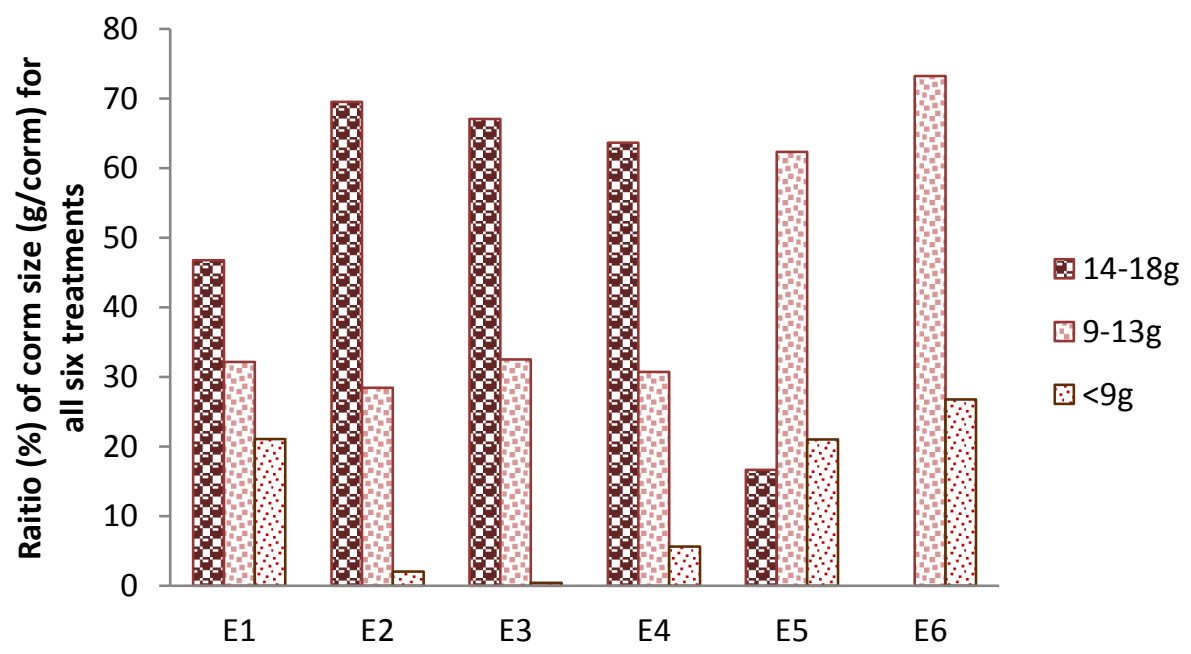

Figure-6. Ratio (\%) of corm size (g/corm) for all six treatments. 
Figure 6 shows that the percentage of corms $>14 \mathrm{~g}$ was greatest in E3, and progressively decreased in the order E2, E4, E1, E5, E6. Thus the two most significant crops in the agricultural economy are E2 and E3.

\subsection{Brix Value in Corms}

The Brix value did not differ among the experimental plots, averaging $7 \pm 1$.

\section{6. $P C A$}

Information from 12 parameters obtained in the six experiments, through PCA, can be displayed by the scores of the two principal components, with $48.1 \%$ and $28.47 \%$ of the variation in data, respectively (Figure 7 ). Only $23.43 \%$ of information in the data was lost.

The positive direction of $\mathrm{PC} 1$ points towards experiments with relatively high biomass, including total weight, stem weight, corm weight, and root weight. It is also includes high stem number and stem diameter. $\mathrm{PC} 2$ is mostly highly correlated with stem height and corm size.

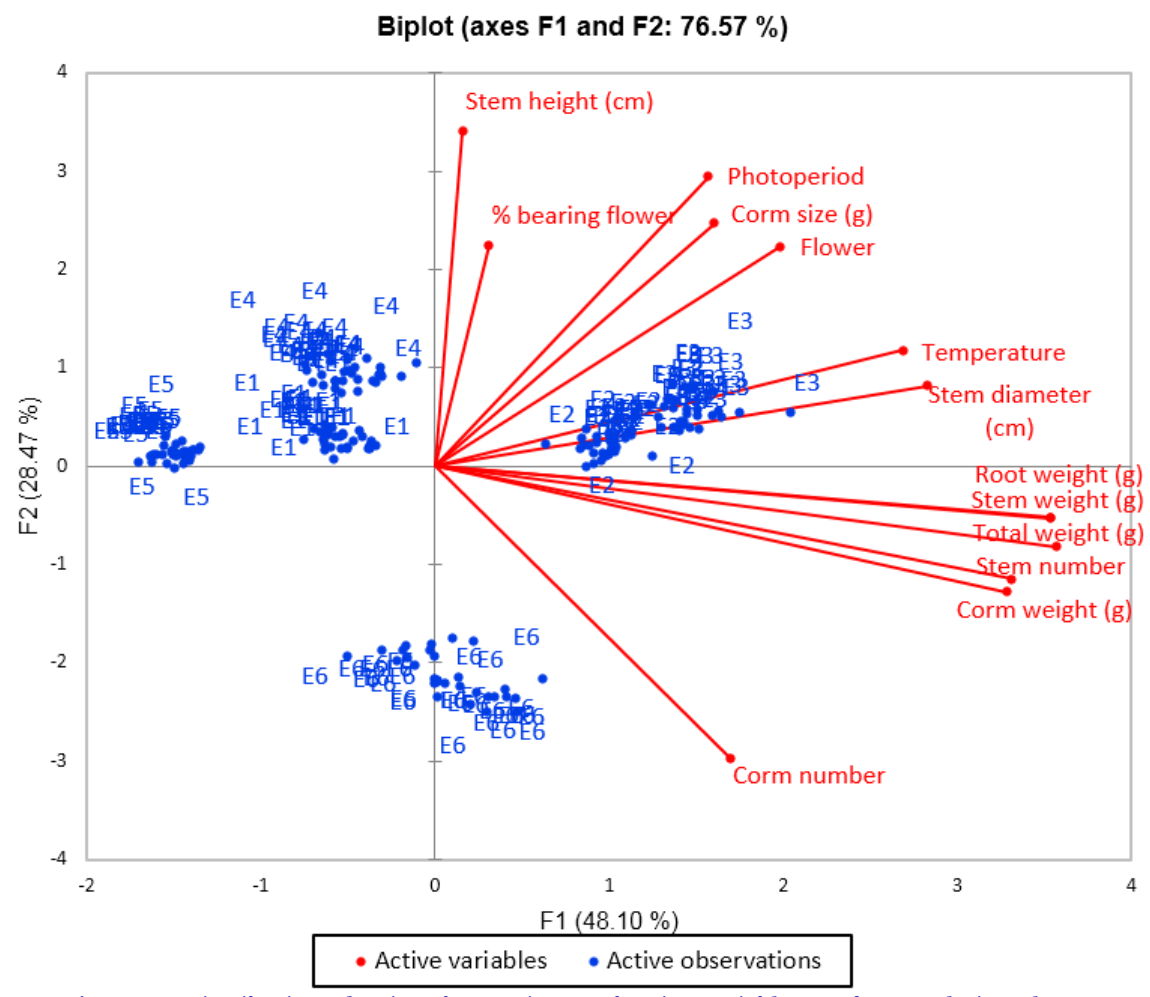

Figure-7. Distribution of active observations and active variables on the correlation plane.

As shown in Figure 7, the six experiments can be classified into three groups. The first group, consisting of E2 and $\mathrm{E}$ 3, has a high yield, the second is E6, which has an intermediate yield while the last group (E1, E4 and E5) shows lower yields. There was no clear relationship between yield and average photoperiod or average daily mean temperature for different times of planting. It was also observed that crop yield (corm weight) has a strong correlation with stem number $(r=0.84)$ and stem weight $(r=0.84)$ (Figure 8$)$. Thus, these two parameters can be used as indicators to project the corm yield of the crop.
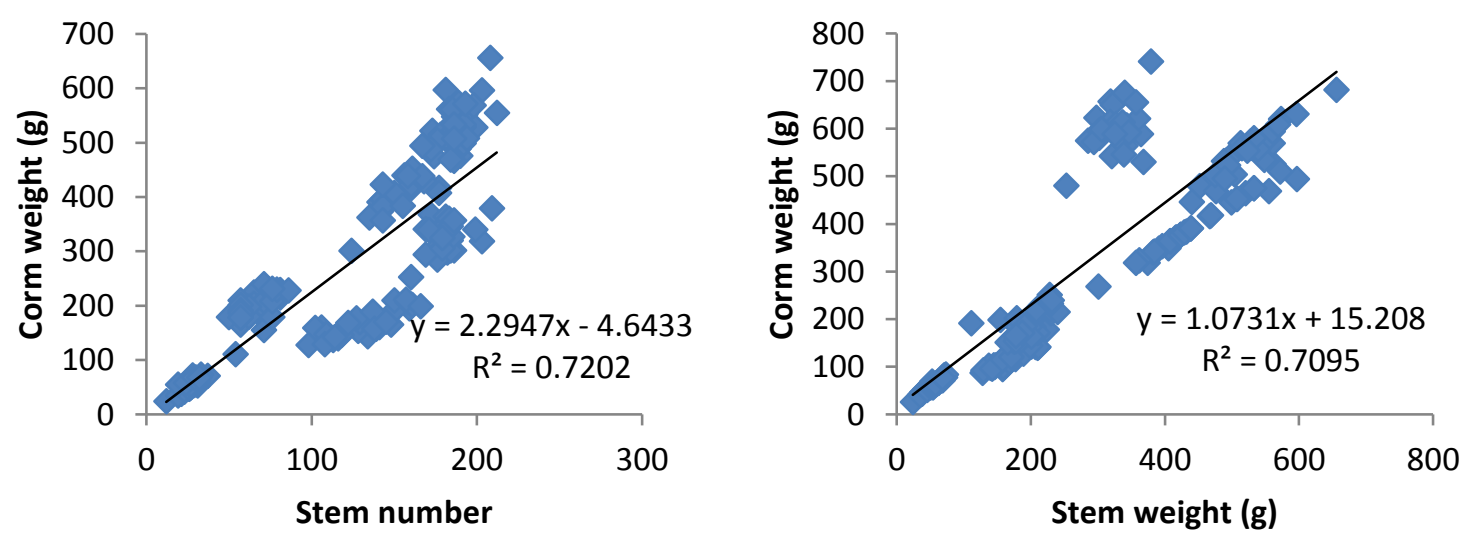

Figure-8. Linear regression between corm weight and stem number (left) and stem weight (right). 


\section{DISCUSSION}

\subsection{Cultivability of Chinese Water Chestnut in the Mekong Delta}

According to Lambers, Hans, and Oliveira (2019), of those species introduced to a site, many lack the physiological traits to survive the physical environment. Results of the present study confirm that Chinese water chestnut cultivated in the Mekong River Delta can survive, grow, and reproduce. Measurements of chlorophyl fluorescence and other growth parameters of plants cultivated at different times of the year showed that it can grow healthily, undergo a growth stage in the first three months and enter the reproductive stage in the last month during the four months of its life cycle. Thus, it has physiological traits to adapt to the physical environment of the Mekong Delta. However, many plant species that are transported to different continents as ornamental or food crops never spread beyond the areas where they were planted, because they cannot compete with native species. However, the occurrence of wild E. dulcis in the Mekong Delta can be considered a reason to believe that Chinese water chestnut can overcome the biotic filter.

\subsection{Suitability of Crop Season for Cultivation of Chinese Water Chestnut in the Mekong Delta}

The total cultivation time of Chinese water chestnut in the Mekong Delta is also lower than in other regions the time from nursery to harvesting was 120-140 days in the Mekong Delta but 220 days in Australia and the USA (Kleinhenz et al., 2001). The duration of daylight for the highest biomass recorded in the corm experiments (for E3 and E2 (Table 3)) was between $12 \mathrm{~h} 28^{\prime}-12 \mathrm{~h} 43^{\prime}$ and $11 \mathrm{~h} 55^{\prime}-12 \mathrm{~h} 25^{\prime}$, respectively. This result is consistent with the study of Mei et al. (2000), which recommended that the critical photoperiod of this crop is between 12h $00^{\prime}$ and $12 \mathrm{~h}$ 30 , and corm formation was promoted by photoperiods shorter than a critical maximum. Thus, we can suggest that the season for cropping of this cultivar in the Mekong Delta is from March to August. This study also found that the experiment E6, with the range of daylight between $11 \mathrm{~h} 32^{\prime}$ and $11 \mathrm{~h} 55^{\prime}$, which was lower than the critical value, had higher yield compared with that of E1, E4, and E5. According to the study by Mei et al. (2000) among photoperiods shorter than the critical value, the shortest photoperiod tended to induce stronger corm formation. In our study, we also observed that plants in experiment E6 produced very early corms (30 days after planting) and the number of corms obtained was the highest. This led to a higher yield in this experiment, even though the photoperiod was not favorable for the growth of this cultivar because, under short days, significantly more dry matter is allocated to corms and rhizomes. On the other hand, it seems that not only daylength but also temperature determines the yield of this plant, because the average temperature of this experiment was $27.7{ }^{\circ} \mathrm{C}$, the lowest among the six experiments. Observation of the production of Chinese water chestnut in Australia suggested that corm formation is associated with shortened photoperiod and cool temperatures, or photoperiod/temperature interaction.

\section{CONLUSIONS}

To sum up, the data presented here suggest that it is possible to cultivate Chinese water chestnut in climates such as those in Can Tho City in the Mekong Delta, with a daily temperature range of $20.6-35.7^{\circ} \mathrm{C}$ and photoperiod between $11 \mathrm{~h} \mathrm{30}$ and 12h 43'. The most suitable growing season starts in April or May and ends in August, because the highest yield will be obtained and it will avoid flood damage in the Mekong Delta, where the flood season is often August-November. Further studies should focus on the biotic interactions of this crop in the Mekong Delta to determine its diseases or natural enemies. In addition, to ensure successful crops, specific experiments should be conducted to determine the level of salinity and flood tolerance in order to minimize the damage caused by saltwater intrusion and floods due to the impacts of climate change.

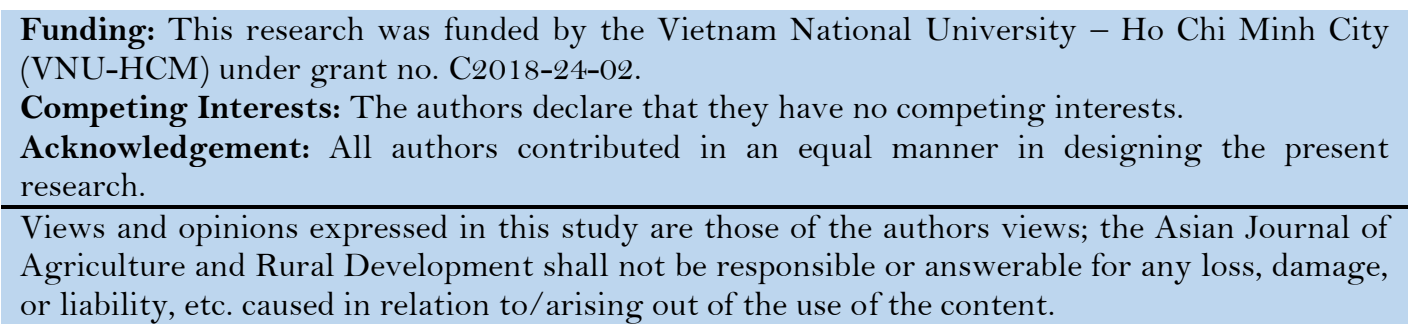

\section{REFERENCES}

Cantho City City Statistics Office. (2019). Cantho city statistical yearbook 2018. Ha Noi: Statistical Publishing House. Cantho City City Statistics Office. (2020). Cantho city statistical yearbook 2019. Ha Noi: Statistical Publishing House.

Critchley, C. (1998). "Photoinhibition." In photosynthesis: A comprehensive treatise, A.S. Raghavendra (pp. 264-272). Cambridge, UK: Cambridge University Press.

Kleinhenz, V., Midmore, D. J., \& Geoff, L. (2001). A grower's guide to cultivating Chinese Waterchestnut in Australia. Kingston, ACT: Rural Industries Research and Development Corporation.

Lambers, Hans, \& Oliveira, R. S. (2019). Plant physiological ecology (3rd ed.): Springer International Publishing.

Mei, L., Kleinhenz, V., Lyall, T., \& Midmore, D. (2000). Response of Chinese water chestnut (Eleocharis dulcis (Burm. f.) Hen sch) to photoperiod. The Journal of Horticultural Science and Biotechnology, 75(January), 72-78. Available at: https://doi.org/10.1080/14620316.2000.11511203.

Morton, J. F., Sanchez, C. A., \& Snyder, G. H. (1988). Chinese waterchestnuts in Florida - past, present, and future. Paper presented at the Proceedings of the... Annual Meeting of the Florida State Horticulture Society (USA). 